\title{
Problems and Countermeasures in Preschool teachers' Performance Evaluation and Index System Assessment
}

\author{
Li'e Li \\ College of education science, Yan'an University, Yan'an 716000, China \\ lilie0716@126.com
}

\begin{abstract}
The performance appraisal index system plays an important role in the preschool teachers' performance appraisal. There exist the three aspects of problem to affect the accuracy and effectively of the teacher assessment, such as the performance appraisal index system confusion, weight design unreasonable and mainly set by the management. In order to design a reasonable performance appraisal index system, the analytic hierarchy process method was adopted to reconstruct the preschool teachers' performance appraisal index system, especially for the each index weight design. And then some suggestions about improving performance appraisal were supplied to improve the preschool teacher's enthusiasm by designing operable evaluation standard, strengthening the training of managers management theory and paying more attention to the effect of kindergarten teachers in assessment.
\end{abstract}

Keywords: Analytical Hierarchy Process; Preschool teachers; Kindergarten; Performance appraisal

\section{幼儿教师绩效考核指标体系存在的问题及对策}

\section{李丽娥}

延安大学教育科学学院, 延安 中国

摘 要: 幼儿教师绩效考核对调动教师工作积极性、开发教师教学潜能具有重要意义。考核的 关键要素在于绩效考核的指标体系, 当前幼儿教师绩效考核指标存在体系混乱、权重设计不 合理、主要由管理者制定三个方面的问题。本研究采用层次分析法重建了幼儿教师绩效考核 指标体系, 确定了各指标的权重; 提高了绩效考核指标的科学性和有效性。针对绩效考核的 问题进一步提出了改进绩效考核的建议,制定具有可操作性的考核标准、加强对管理者管理理 论的培训、重视幼儿园教师在考核中的作用。

关键词：层次分析法；幼儿教师；幼儿园；绩效考核

\section{1. 前言}

随着人事制度的改革, 幼儿园管理者对教师实施考核成为常规管理工作的一部分。考核指标 体系是幼儿园教师绩效考核的核心内容, 是影响绩效考核结果的关键因素。设计并采用符合 幼儿教师职业特点的绩效考核体系利于幼儿园加强教师管理, 对调动教师工作积极性、开发 教师教学潜能具有重要意义。

\section{2. 幼儿园绩效考核指标存在的问题}

\section{1. 绩效考核指标体系混乱}

2012 年, 教育部发布《幼儿园教师专业标准（试行）》，规定了合格幼儿教师在专业理念与 师德、专业知识和专业能力等方面的基本要求, 同时提出以此文件作为幼儿教师绩效管理的 重要依据。同年，教育部等部门下发的《关于加强幼儿园教师队伍建设的意见》中提出：“完 善符合幼儿园教师工作特点的评价标准, 重点突出幼儿园教师的师德、工作业绩和保教能力。” 
明确了幼儿教师绩效考核的关键指标。在实践中, 幼儿园往往又把“勤”作为考核的一项重要 内容, 由此, 德、能、勤、绩成为幼儿教师绩效考核的四项一级指标。在一级指标下, 我们 划分出多项二级指标, 如保教能力又可以划分为环境创设与利用、教育活动计划、家园共育 等。然而, 很多幼儿园制定的考核指标体系混乱, 并无一级指标和二级指标的划分。这种做 法一方面表明了幼儿园绩效考核指标设立的盲目性, 另一方面不利于对考核结果进行综合、 系统的评价和分析。

2.2. 绩效考核指标的权重设计不合理

权重是绩效考核指标在总分中所占的比例。由于各考核指标的重要性程度是不一致的, 因此 其权重分配也应有所差异。幼儿教师绩效考核指标的确定，应根据教师岗位要求的侧重点， 慎重评估某一指标在指标体系中的作用, 合理分配权重。然而实践中, 很多幼儿园管理者虽 然都会制定非常详尽的考核指标体系, 基本能够涵盖幼儿教师在德、能、勤、绩四个方面的 内容。但指标体系的设计存在突出的问题是所有考核指标权重平均分配, 导致考核不能真实 反映教师工作的实际情况, 缺乏对幼儿教师工作重心的引导。

2.3. 考核指标主要由管理者制定

教师作为被考核者, 对考核指标有一定的话语权。但通览幼儿园绩效考核工作的过程, 各个 环节往往都是自上而下开展的。考核指标是由管理者根据日常管理经验或参考其他园所考核 指标提出, 然后对个别优秀教师访谈, 征求对考核指标及方法的意见和建议, 修改补充后由 管理层讨论通过并监督实施。幼儿教师作为被考核的对象, 只有个别教师对考核指标的制定 有建议权，大多教师无从知晓考核指标制定的过程，更难以选择合适的考核方法。

\section{3. 应用层次分析法建立教师绩效考核指标体系}

层次分析法(Analytical Hierarchy Process, 简称 AHP)是美国运筹学家 A.L.Saaty 提出的一种将 定性和定量相结合的问题解决方法, 它利用较少的定量信息, 通过各个因素的两两对比和对 结果的检验, 从而确定各因素的权重。主要有三个步骤:

3.1 建立考核指标的层次结构

根据幼儿园绩效考核的实践并参照《幼儿园教师专业标准（试行）》建立关键绩效考核指标, 并分解出二级、三级指标，形成幼儿园教师考核指标层次结构表。如表 1 所示:

表1 幼儿园教师考核指标层次结构

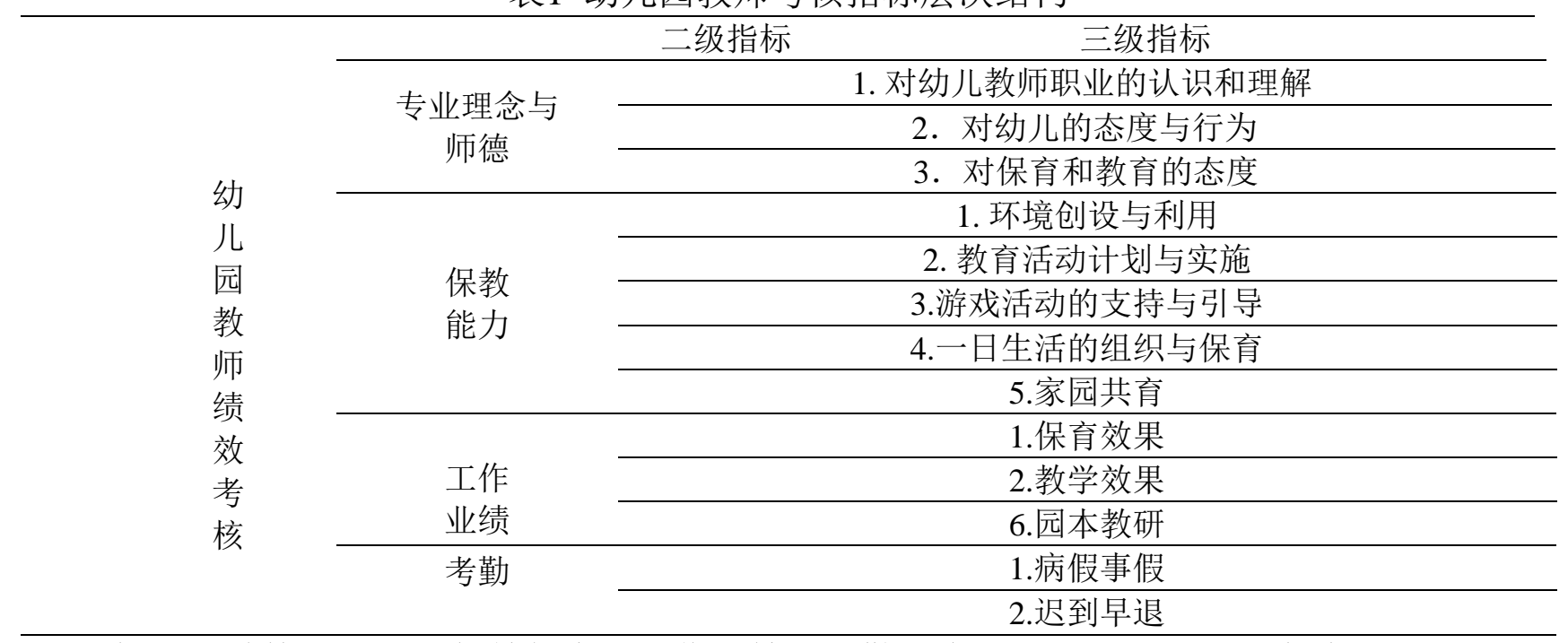

该指标层次结构从师德、保教能力、工作业绩和考勤四个方面进行设计, 并在此基础上进一 步细化, 能够较为全面地反映教师的工作实际情况。 


\section{2 建构判断矩阵}

权重是指考核指标在总分中所占的比例, 是考核指标在整个指标体系中重要性的表现。因此, 根据幼儿园教师工作的特殊性确定绩效考核体系中的各项指标的权重尤为重要。权重的确定 采用表 2 所示的 1-9 的比例标度法来进行:

\begin{tabular}{|c|c|}
\hline & 标度 \\
\hline & 表示两个因素先比, 具有同样重要性 \\
\hline 3 & 表示两个因素相比, 一个因素比另一个因素稍微重要 \\
\hline 5 & 表示两个因素相比, 一个因素比另一个因素明显重要 \\
\hline 7 & 表示两个因素相比, 一个因素比另一个因素强烈重要 \\
\hline 9 & 表示两个因素相比, 一个因素比另一个因素极端重要 \\
\hline & 2、4、6、8 上述两相邻判断的中值 \\
\hline 倒数 & 因素 $\mathrm{i}$ 与 $\mathrm{j}$ 比较的判断 $A i j$, 则因素 $\mathrm{j}$ 与 $\mathrm{i}$ 比较的判断值 $A j i=1 / a i j$ \\
\hline
\end{tabular}

\section{3 确定各个指标的权重}

通过对二级、三级指标进行两两比较并赋值, 构造判断矩阵。并采用一致性检验的办法避免 自相矛盾, 通过计算最终确定各因素的权重。研究采用北京欣晟软件公司开发的 AHP 软件进 行权重计算，并对结果进行一致性检验，见表 3、表 4、表 5、表 6、表 7。

表3 幼儿园绩效考核一级指标权重

\begin{tabular}{cccccc}
\hline $\begin{array}{c}\text { 幼儿园教师 } \\
\text { 绩效考核 }\end{array}$ & 师德 & 工作业绩 & 保教能力 & 考勤 & 权重 \\
\hline 师 德 & 1.0000 & 0.3333 & 0.3333 & 3.0000 & $\begin{array}{c}0.1513 \\
\text { C.R. }=0.0604 \\
0.2737\end{array}$ \\
工作业绩 & 3.0000 & 1.0000 & 0.3333 & 4.0000 & $\begin{array}{c}\text { (max }=4.1613 \\
\text { 保教能力 } \\
\text { 考 勤 }\end{array}$ \\
\hline
\end{tabular}

采用上述方法，通过赋值计算得到各二级指标在所在一级指标中的权重：

表4 幼儿园绩效考核二级指标“师德”权重

\begin{tabular}{ccccc}
\hline 师 德 & 职业认同 & $\begin{array}{c}\text { 对幼儿的 } \\
\text { 态度与行为 }\end{array}$ & 保教态度 & 权重 \\
\hline $\begin{array}{c}\text { 对幼儿教师职业的认 } \\
\text { 识理解 }\end{array}$ & 1.0000 & 0.3333 & 0.2500 & 0.1263 \\
对幼儿的态度与行为 & 3.0000 & 1.0000 & 1.0000 & $\begin{array}{c}\text { C.R. }=0.0089 \\
0.4160\end{array}$ \\
对保育教育的态度 & 4.0000 & 1.0000 & 1.0000 & $\lambda$ max=3.0092 \\
\hline
\end{tabular}

表5 幼儿园绩效考核二级指标“工作业绩”权重

\begin{tabular}{cccccc}
\hline 工作业绩 & 保育效果 & 教学效果 & 园本教研成绩 & \multicolumn{2}{c}{ 权重 } \\
\hline 保育效果 & 1.0000 & 3.0000 & 3.0000 & 0.5889 & C.R.=0.0518 \\
教学效果 & 0.3333 & 1.0000 & 2.0000 & 0.2519 & $\lambda$ max $=3.0539$ \\
园本教研成绩 & 0.3333 & 0.5000 & 1.0000 & & 0.1593 \\
\hline
\end{tabular}


表6 幼儿园绩效考核二级指标“保教能力”权重

\begin{tabular}{|c|c|c|c|c|c|c|}
\hline 保教能力 & $\begin{array}{l}\text { 家园 } \\
\text { 共育 }\end{array}$ & $\begin{array}{l}\text { 一日生 } \\
\text { 活组织 } \\
\text { 与保育 }\end{array}$ & $\begin{array}{c}\text { 游戏活动 } \\
\text { 支持与引 } \\
\text { 导 }\end{array}$ & $\begin{array}{l}\text { 环境创 } \\
\text { 设 } \\
\text { 与利用 }\end{array}$ & $\begin{array}{l}\text { 教育活动 } \\
\text { 计划与实 } \\
\text { 施 }\end{array}$ & 权重 \\
\hline 家园共育 & 1.0000 & 0.5000 & 0.2500 & 0.5000 & 0.2500 & 0.0814 \\
\hline $\begin{array}{c}\text { 一日生活的组织与 } \\
\text { 保育 }\end{array}$ & 2.0000 & 1.0000 & 2.0000 & 1.0000 & 1.0000 & 0.2467 \\
\hline $\begin{array}{c}\text { 游戏活动支持与引 } \\
\text { 导 }\end{array}$ & 4.0000 & 0.5000 & 1.0000 & 1.0000 & 1.0000 & $\begin{array}{c}0.2143 \\
\text { C.R. }=0.0437\end{array}$ \\
\hline 环境创设与利用 & 2.0000 & 1.0000 & 1.0000 & 1.0000 & 0.5000 & $\begin{array}{c}0.1819 \\
\lambda \max =5.1960\end{array}$ \\
\hline $\begin{array}{c}\text { 教育活动计划与实 } \\
\text { 施 }\end{array}$ & 4.0000 & 1.0000 & 1.0000 & 2.0000 & 1.0000 & 0.2757 \\
\hline
\end{tabular}

表7 幼儿园绩效考核二级指标“考勤”权重

\begin{tabular}{ccccc}
\hline 考 勤 & 病假事假 & 迟到早退 & 权重 & \\
\hline 病假事假 & 1.0000 & 4.0000 & 0.8000 & C.R. $=0.0000$ \\
迟到早退 & 0.2500 & 1.0000 & 0.2000 & $\lambda \max =2.0000$ \\
\hline
\end{tabular}

以上结果显示, 各指标的 C.R. 小于 0.10 , 即通过该矩阵确定的各个指标的权重可以应用。由 此得出幼儿园教师绩效考核各级考核指标权重, 见表 8:

表8 幼儿园教师绩效考核各级考核指标权重

二级指标及权重 三级指标及权重

\begin{tabular}{ccc}
\hline \multirow{2}{*}{ 师德 } & \multicolumn{3}{c}{ 1. 对幼儿教师职业的认识和理解 0.1513} \\
\cline { 2 - 3 } 0.1599 & 2.对幼儿的态度和行为 & 0.0629 \\
\cline { 2 - 3 } & 3.对保育和教育的态度 & 0.0692 \\
\hline & 1. 环境创设与利用 & 0.0722 \\
\cline { 2 - 3 } 保教能力 & 2. 教育活动计划与实施 & 0.1404 \\
0.5094 & 3.游戏活动的支持与引导 & 0.1092 \\
\cline { 2 - 3 } & 4.一日生活的组织与保育 & 0.1257 \\
\hline & 5.家园共育 & 00415 \\
\hline 工作业绩 & 1.保育效果 & 0.1612 \\
\hline 0.2737 & 2.教学效果 & 0.0689 \\
\hline 考勤 & 6.园本教研 & 0.0436 \\
0.0656 & 1.病假事假 & 0.0525 \\
\hline & 2.迟到早退 & 0.0131 \\
\hline
\end{tabular}

由各二级指标的权重可以看出, 师德、保教能力和工作业绩的权重相对较高, 基本符合教育 部门对幼儿教师考核的要求。而应用层次分析法进行绩效考核指标权重的设计能够提高其科 学性, 减少盲目性和随意性, 提高绩效考核的效率。

\section{4. 改进幼儿园绩效考核的建议}

科学有效的绩效考核指标体系对提升教师队伍的专业素养、促进教师专业发展有重要作用。 针对该幼儿园绩效考核指标存在的问题, 除重建考核指标体系外, 还应着重从以下几个方面 努力: 


\section{1 制定具有可操作性的考核标准}

绩效考核的标准是指对被考核者目标达成程度的衡量, 考核标准的直观性、可操作性直接影 响到考核结果的质量。针对幼儿园难以操作的定性考核标准应尽可能用定量的方式来对教师 进行考核。采用具体、可测量的数字来对幼儿教师进行考核, 在实践中更容易操作, 避免定 性考核的误差。

\section{2 加强对管理者管理理论的培训}

幼儿园管理者多从优秀教师中提拔, 他们虽然拥有丰富的教学经验和幼教理论素养, 但管理 理论贫乏。同时, 幼儿园繁忙的工作也让他们无暇学习和钻研管理学知识, 因此他们对幼儿 园的管理往往停留在经验管理阶段。为进一步提高办园质量, 提高幼儿园管理水平, 应着重 加强管理者管理理论的培训和学习, 有计划的通过让她们参加研讨会、短期学习、脱产进修 等在职学习, 熟练掌握教育评价、教育统计、绩效管理等方面的知识, 完善管理者的知识结 构，为能够把握教师考核评价的规律、较好地完成幼儿园教师绩效考核工作打下基础。

4.3 重视幼儿园教师在考核中的作用

《幼儿园教育指导纲要（试行）》提出“幼儿园教育工作评价实行以教师自评为主，园长及有 关管理人员、其他教师和家长参与评价的制度”，提出了幼儿园教育评价工作主体的多样性。 幼儿园教师考核作为幼儿园教育工作评价的一部分, 也不应该是幼儿园管理者独立完成的工 作, 而应是由包括教师在内的多元主体共同参与的。首先, 考核方案应由全体教职工会议或 教职工代表会议讨论后制定, 由教师参与制定出来的考核方案更容易被他们接受和支持。其 次，重视幼儿教师作为评价主体的自我评价，让幼儿教师在自我评价中不断成长。

\section{Acknowledgements}

本论文为陕西省教育科学“十二五”规划课题“幼儿园早期阅读教学研究---以延安市为例”阶段 性成果，课题编号 SGH140588；受延安大学教育科学学院院级课题经费资助。

\section{References}

[1] JinRong O,Hao Chen,JunTang. Thinking and Exploration in university teachers' evaluation under the appointment system,Journal of huazhong agricultural university (social science edition), Vol.50 (2003),NO.4,p.93-96

[2] Junyou Zhang. An Objective View on Teacher Performance Assessment and Teacher Professional Development Assessment, Journal of Educational Studies, Vol.3(2007),No. 2,p.47-53

[3] Sheng Zhang. Higher vocational college teachers' performance appraisal system design, Journal of henan normal university (philosophy and social sciences edition), Vol.36 (2009),No. 2, p.234-236

[4] Yuefei Xu. Preschool teachers' professional development stages and kindergarten teacher evaluation research, education Tribune, (2010), No.6, p. 74-77 